University of Wollongong

Research Online

Faculty of Engineering and Information

Faculty of Engineering and Information

Sciences - Papers: Part B

Sciences

2018

Supporting Physics Teachers to Deliver the New High School Certificate Syllabus: What are the Priorities?

Lorna E. Jarrett

University of Wollongong, lornaj@uow.edu.au

Helen Georgiou

University of Wollongong, helengeo@uow.edu.au

Michael L. F Lerch

University of Wollongong, mlerch@uow.edu.au

George J. Takacs

University of Wollongong, gjt@uow.edu.au

William J. Zealey

University of Wollongong, zealey@uow.edu.au

Follow this and additional works at: https://ro.uow.edu.au/eispapers1

Part of the Engineering Commons, and the Science and Technology Studies Commons

Research Online is the open access institutional repository for the University of Wollongong. For further information contact the UOW Library: research-pubs@uow.edu.au 


\title{
Supporting Physics Teachers to Deliver the New High School Certificate Syllabus: What are the Priorities?
}

\author{
Abstract \\ For the first time since 2000, the New South Wales High School Certificate (HSC) school-leavers' Physics \\ syllabus has been updated. Topics not taught in schools since 2000 have been reintroduced, the number \\ of mandated equations has more than doubled, and students must now do 15 hours of individual or group \\ investigations in both Years 11 and 12. The Vniversity of Wollongong (UOW) intends to support teachers \\ in our local area by providing outreach and professional learning activities for teachers and students. To \\ determine teachers' priorities, we invited teachers to complete a short online survey. Respondents stated \\ that they were very likely to access activities and resources, and that their top priorities were accredited \\ professional learning workshops and support with depth studies.

\section{Disciplines} \\ Engineering | Science and Technology Studies

\section{Publication Details} \\ Jarrett, L., Georgiou, H., Lerch, M., Takacs, G. \& Zealey, W. (2018). Supporting Physics Teachers to Deliver \\ the New High School Certificate Syllabus: What are the Priorities?. 2018 IEEE International Conference on \\ Teaching, Assessment, and Learning for Engineering (TALE) (pp. 798-801). United States: IEEE.
}




\section{Supporting Physics Teachers to Deliver the New High School Certificate Syllabus: What are the Priorities?}

\author{
Lorna Jarrett \\ School of Physics \\ University of Wollongong \\ Wollongong, Australia \\ lornaj@uow.edu.au \\ George Takacs \\ School of Physics \\ University of Wollongong \\ Wollongong, Australia \\ git@uow.edu.au
}

\author{
Helen Georgiou \\ Faculty of Social Sciences \\ University of Wollongong \\ Wollongong, Australia \\ helengeo@uow.edu.au \\ William Zealey \\ School of Physics \\ University of Wollongong \\ Wollongong, Australia \\ zealey@uow.edu.au
}

\author{
Michael Lerch \\ School of Physics \\ University of Wollongong \\ Wollongong, Australia \\ mlerch@uow.edu.au
}

\begin{abstract}
For the first time since 2000, the New South Wales High School Certificate (HSC) school-leavers' Physics syllabus has been updated. Topics not taught in schools since 2000 have been reintroduced, the number of mandated equations has more than doubled, and students must now do 15 hours of individual or group investigations in both Years 11 and 12. The University of Wollongong (UOW) intends to support teachers in our local area by providing outreach and professional learning activities for teachers and students. To determine teachers' priorities, we invited teachers to complete a short online survey. Respondents stated that they were very likely to access activities and resources, and that their top priorities were accredited professional learning workshops and support with depth studies.
\end{abstract}

Keywords-physics education, years 11-12, secondary education, professional learning

\section{BACKGROUND AND RATIONALE}

The NSW Education Standards Authority (NESA) has updated the State High School Certificate (HSC) schoolleavers' physics syllabus for the first time since 2000 . The new syllabus is currently being taught to Year 11 students. Teachers and students will encounter several significant changes. Topics such as motion in two dimensions, wave properties of light and thermodynamics, which have not been part of the NSW syllabus since 2000 [1], have been reintroduced. Mathematical rigour has also been increased: the number of mandated equations has risen from 40 to 82 [2]. In addition, students must carry out fifteen hours of depth studies in both Years 11 and 12. Depth studies involve "any type of investigation/activity that a student completes individually or collaboratively that allows the further development of one or more concepts found within or inspired by the syllabus" [3]. They represent a significant novel addition to the syllabus.

Elements have also been removed from the syllabus. Students are no longer required to discuss the social and historical context of scientific discoveries, or the implications of technologies for society and the environment. Along with the increase in mandated equations these changes imply a marked decrease in the degree to which students will be expected to answer essay-style questions. Optional topics, which had previously allowed teachers to specialise in an area of study, have also been removed. This means that medical physics, geophysics and semiconductors no longer appear in the syllabus. References to superconductors, which were previously discussed qualitatively, have also been removed.

These changes pose a number of new challenges for both teachers and students. They require teachers to deliver, and students to learn more advanced mathematical skills. They also require teachers to guide students as they design, carry out and report on individual or group research on topics and concepts not explicitly covered in the syllabus. Teachers must also assess these research reports. In addition, some teachers will have to deliver content that they have not formally encountered in their own education, as reports illustrate that $20 \%$ of current physics teachers are not physics-trained [4], and the syllabus now contains concepts that have not been taught in NSW schools for 20 years.

It is therefore likely that teachers will require support in order to deliver the new curriculum successfully [5]. This is particularly the case in rural, regional and lower socioeconomic areas, where physics teachers are less likely to have studied the subject at tertiary level and experience a range of other barriers compared to their metropolitan counterparts [4]. Physics classes in these schools already tend to be smaller than in other schools and there is a risk that such schools may not be able to offer the new physics syllabus to students, either because of a critical drop in student numbers or because no suitably qualified teacher is available [5]. However, unlike the introduction of the K-10 Australian Curriculum, no additional funding has been made available to assist teachers and schools in making the transition. Therefore, support from universities and other institutions, particularly in rural, regional and low socioeconomic areas, is a social equity issue [2].

\section{METHODS}

To help teachers address these challenges and implement the new syllabus successfully, a team from the University of 
Wollongong (UOW) intends to develop and offer professional learning and other forms of outreach for schools in our catchment area. Our team includes members with in-depth teaching and learning experience in both high school education and university physics. We have two former high school physics teachers with PhDs in physics education and significant experience in survey research, and two physics lecturers with nearly 60 years of school outreach experience between them.

UOW's main campus is situated in Wollongong, $85 \mathrm{~km}$ south of Sydney, and we have satellite campuses in Liverpool and Loftus in Sydney; and Bateman's Bay, Bega, Nowra and Moss Vale in the South Coast and Southern Highlands. UOW is therefore the closest university for schools in the Illawarra, South Coast, Southern Highlands, Wingecarribee areas, and parts of McArthur. To ensure that we meet teachers' needs for professional learning and/or support, we have started a consultation process with physics teachers in these areas to determine their priorities.

The first phase of consultation was designed to minimise inconvenience to teachers and consisted of a short online survey, comprising ten questions. The first two listed authors have extensive experience in survey design [6], [7]. We designed the survey with a combination of Likert, sliding scale, check-boxes and optional open-ended questions, in order to minimise burden of time to teachers while maximising the opportunity for teachers to communicate their thoughts and priorities fully.

We asked to what extent teachers would like support with each of the syllabus topic areas; to what extent they would like to see different types of activities offered; what their top two training/outreach priorities were; where they would like training to be provided; how likely in practice they would be to access activities; what factors would hinder them from accessing activities; and how important it is for any professional learning to be endorsed by NSW Education Standards Authority (NESA). We also provided additional space for further comments or suggestions and asked for some basic demographic data: the number of years teaching physics and the number of physics teachers in the school.

\section{FINDINGS}

We invited physics teachers in 57 schools in our catchment area (including thirteen in regional areas and nine low socioeconomic schools [8]) to complete our survey. We received 32 responses; an excellent response rate for online surveys and indicative of strong interest [9]. Among respondents, the mean number of years teaching senior physics was seven with a standard deviation of six and a median of five, and the mean and median numbers of physics teachers in the school were two, with a standard deviation of one.

Fig. 1 shows responses to the question: How much would you like professional development or other support offered to teachers and/or students of the following content areas of the new Physics syllabus?

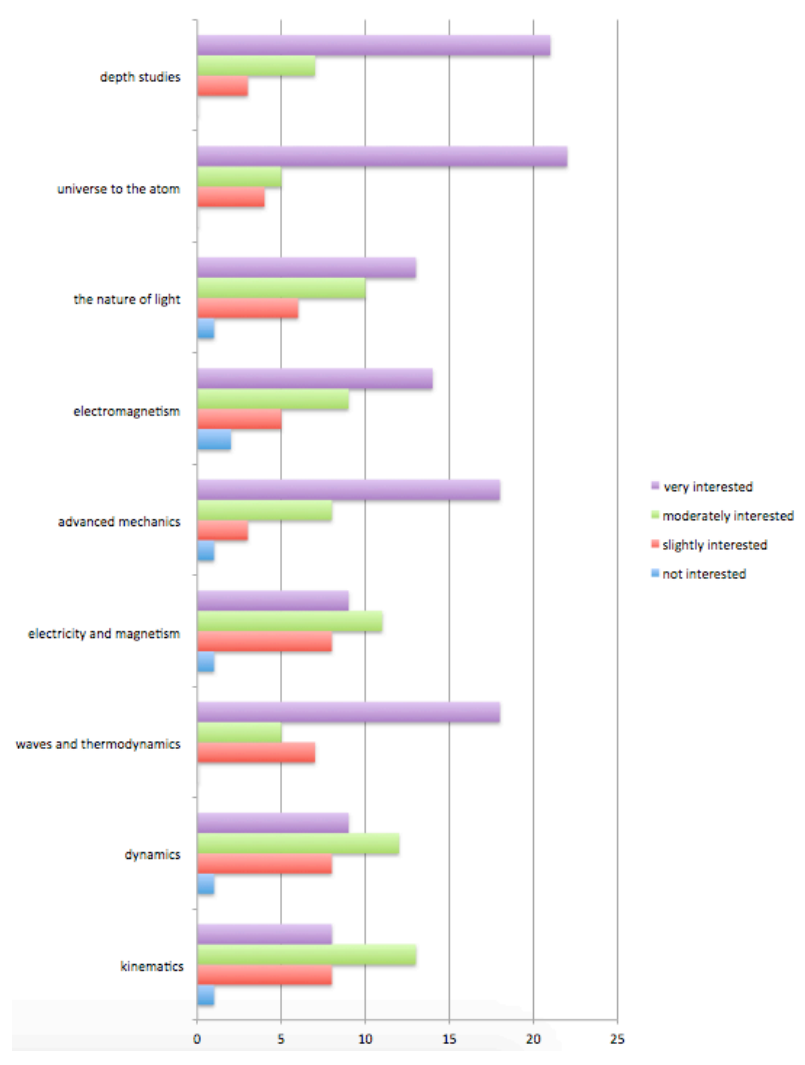

Fig. 1. Respondents' priorities for content area.

Respondents' top priorities were "From the Universe to the Atom" topic, depth studies, "Waves and Thermodynamics" topic and "Advanced Mechanics" topic. All of these involve content that may be unfamiliar to teachers. The "Universe to the Atom" topic largely corresponds to the Quanta to Quarks option of the previous syllabus. This option was answered by $51 \%$ of students in 2017 , so it is possible that up to $49 \%$ of teachers have not taught this content before [10]. The next most highly rated area concerned depth studies, which as explained above, are a new introduction to the HSC syllabus. "Waves and Thermodynamics" and "Advanced Mechanics" both contain content which has not been part of the HSC syllabus in 20 years. However, not all new or reintroduced content is a high priority for teachers: for example Kirchoff's Laws and quantitative treatment of electrical resistors in series and parallel have been reintroduced, however only nine respondents expressed strong interest in the "Electricity and Magnetism" topic.

Fig. 2 shows responses to the question: How much would you like to see the following types of support or professional development offered?

Interestingly, respondents were most interested in workshops for teachers including theory and experiments, experiments only and on depth studies, but there was little interest on teacher workshops focusing only on content. This suggests that despite a reduction in prescribed practical investigations [1], teachers place a high value on being prepared to deliver experiments in the physics classroom. 


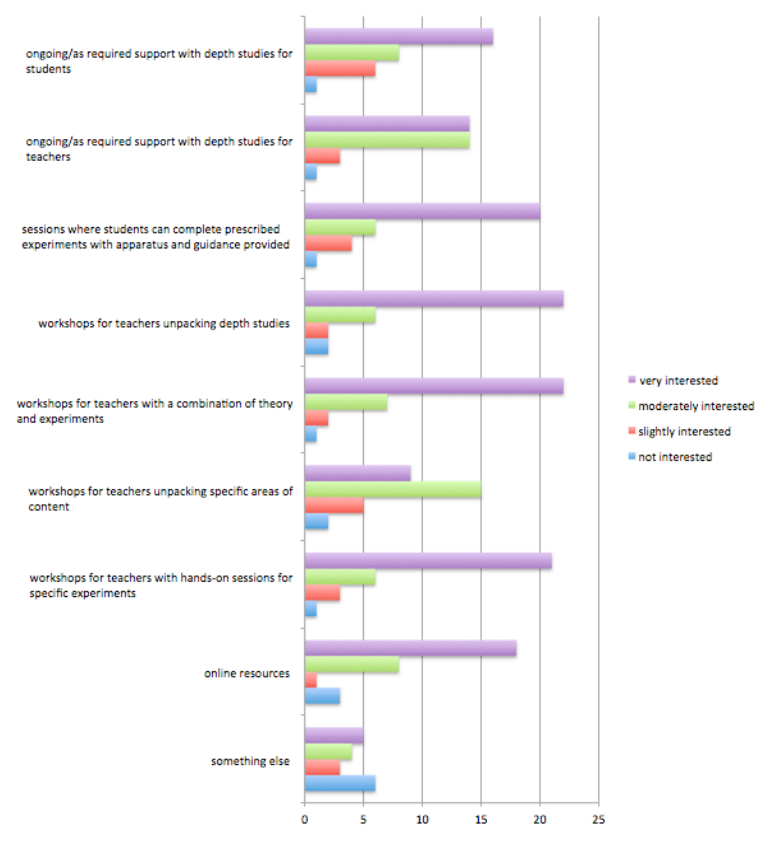

Fig. 2. Respondents' priorities for format.

Several respondents commented that availability of resources and equipment at their schools was an issue. These teachers suggested a number of ways of addressing the problem including excursions to the university; visits by the university to their school; videos and simulations of experiments. Many of the teachers who responded "something else" suggested exam-style questions, worked examples, examwriting workshops, example assessments and marking rubrics. This suggests that some teachers are concerned with assessing students' performance in the new syllabus. Teachers also mentioned that they would like to see something similar to the extensive resources provided for the previous syllabus by other universities.

We asked teachers to nominate their top two priorities. We did this to ensure that we understood not only the degree to which teachers were interested in outreach activities and resources, but also which activities were most important to them. This is important because universities are able to offer only a finite number of outreach activities and we want to be sure that we are focusing on teachers' top needs.

Eleven respondents cited content-focused teacher workshops as their first choice. Eight of these wanted to see a combination of theory and experiments offered, while a further two mentioned experiments. Seven respondents' top priority related to depth studies. Of these, three specified that they would like support to be offered directly to students. Six respondents asked for sessions where students could complete experiments with apparatus provided.

Eight respondents cited depth studies as their second choice. Of these, four specified workshops unpacking depth studies, and two specified ongoing support. Seven respondents asked for online resources as their second priority; two of these specified that they would like animations to be provided. For five respondents, second priority was for sessions where students could complete experiments. Five respondents wanted teacher workshops, three of these specified experiments and four mentioned content.

Teachers rated their likelihood of accessing our proposed outreach activities at $81 \%$, and the importance of NESAendorsement at $83 \%$. Lack of available time was the most commonly cited reason for teachers being unlikely to access support or professional learning.

One teacher commented on the similarity between the new HSC syllabus and the International Baccalaureate (IB) program for physics [11]. This raises the possibility that some existing resources developed for the physics IB may have the potential to be used by teachers and students of the new HSC physics syllabus.

\section{CONCLUSION}

These findings suggest an overall strong demand for support. In particular, respondents prioritised NESA-endorsed professional learning workshops combining theory and experiments. The topics of most concern to respondents are "From the Universe to the Atom", and to a lesser extent, "Advanced Mechanics" and "Waves and Thermodynamics". There is also strong demand for a variety of forms of support with depth studies; however as with prescribed content, respondents were most keen on accredited professional learning workshops for delivering depth studies rather than, for example ongoing support being provided to teachers.

A significant number of respondents also wanted to see sessions offered where students can complete prescribed experiments on campus. This raises the question of whether the new syllabus involves experiments related to content not covered in the previous syllabus, or whether the shortage of apparatus that some teachers described is a long-standing problem. Many of the schools for which UOW is the closest university, are located a significant distance from our main campus. For these schools, student excursions to our main campus may not be practicable. However, many of these schools are the regional and low-socioeconomic schools most likely to have physics teachers who are not trained in the subject [2]. Therefore other strategies may have to be developed to support these schools. Online learning may have a role to play here. One possibility recently discussed by our team would involve providing a combination an excursion and online resources and support for depth studies.

Because our focus is on teachers' priorities for delivering the new syllabus, we did not ask teachers about the impact of the removal of elements such as optional topics, from the syllabus. However the introduction of depth studies may mitigate the impact of removal of optional topics, and the associated loss of specialist content such as medical physics. As has been stated previously, the new syllabus places no limitations on the topics students can choose to explore in depth studies, so they offer a possible solution for teachers, students and other stake-holders to include content has been 
removed from the prescribed syllabus.

It should be noted that despite the increased mathematical rigour of the new syllabus, no teacher raised mathematics skills as a possible focus of professional learning or outreach. It may be useful to explicitly address the possible need for support with mathematics skills in future research.

\section{NEXT STEPS}

Our ultimate aim is to devise a sustainable model of outreach to strengthen school-university ties and provide this much needed support.

To this end, further work will involve:

- Determining the specific theory and practical content that we should focus on within the most commonly requested topics. In order to do this, we will examine the new HSC syllabus in further detail, and invite interested teachers to phone or face-to-face discussions to draw out more detailed information about which specific elements of the syllabus are of concern to them, and what they want and need from the schooluniversity partnership. Some respondents have already expressed willingness to engage in such further discussion.

- Continuing to collect information about other forms of support available to teachers of the new HSC physics syllabus, in order to ensure that we are addressing unmet needs and focusing our efforts on the specific needs of teachers in our local area.

- Analysing the International Baccalaureate program for physics and comparing it with the new HSC physics syllabus in order to determine the degree of similarity between the two courses.

- Building on existing school-university partnerships and relationships to facilitate information sharing between schools, and between schools and our institution.

- Using the information collected to develop outreach and professional development activities and resources to run later this year and next year.

- Seeking feedback from participants in, and users of resources and partnerships that we develop, in order to further refine and improve our support to teachers and schools.

\section{ACKNOWLEDGMENT}

We would like to acknowledge the participation of the physics teachers who took the time to complete our survey, as well as Head Teachers and other school staff who helped to distribute the survey.

\section{REFERENCES}

[1] G. H. Nguyen, "The current and new physics stage 6 syllabus-a mapping exercise," Sci. Educ. News, vol. 66, no. 3, pp. 65-66, Sep. 2017.

[2] S. Crook. (2017, Feb. 22). New physics syllabus raises the bar, but how will schools clear it? [Online]. Available: $\mathrm{http}$ ://theconversation.com/new-physics-syllabus-raises-the-bar-but-howwill-schools-clear-it-73370

[3] NSW Education Standards Authority. (2017). Physics stage 6 syllabus [Online]. Available:

http://educationstandards.nsw.edu.au/wps/portal/nesa/11-12/stage-6learning-areas/stage-6-science/physics-2017

[4] P. Weldon, "The teacher workforce in Australia: supply, demand and data issues," Aust. Council for Educ. Res., Adelaide, Australia, Mar. 2015.

[5] H. Georgiou and S. Crook, "Watching the pendulum swing: Changes in the NSW physics curriculum and consequences for the discipline," Sci. Educ. News, vol. 67, no. 1, pp. 20-24, Mar. 2017.

[6] L. Jarrett, B. Ferry and G. Takacs, "Development and validation of a concept inventory for introductory-level climate change science," Int. J. Innovation Sci. Math. Educ., vol. 20, no. 2, pp. 25-41, 2012.

[7] D. Field et al., "Soil science teaching principles," Geoderma, vol. 167168, pp. 9-14, Nov. 2011.

[8] K. Carr. (2014). Low SES School Communities National Partnership [Online]. Available: https://www.aph.gov.au/Parliamentary_Business/Senate Estimates/eetctt e/estimates/add1314/educationindex

[9] C. Robson, Real World Research, 3rd ed. Chichester, UK: Wiley, 2011.

[10] NSW Education Standards Authority. (2018, May 25). Email communication.

[11] International Baccalaureate. (n.d.). Physics [Online]. Available: https:/www.ibo.org/programmes/diplomaprogramme/curriculum/sciences/physics/ 